\title{
Prof. dr. Mitja Skubic (19.12.1926 - 16.9.2015)
}

El 16 de septiembre falleció el profesor Mitja Skubic, profesor emérito de la Universidad de Ljubljana, filólogo romanista y profesor en el Departamento de Lenguas y Literaturas Romances de la Facultad de Filosofía y Letras de dicha universidad. Fue profesor de italiano y de filología románica comparada; a partir de 1981, cuando gracias a su empeño fueron

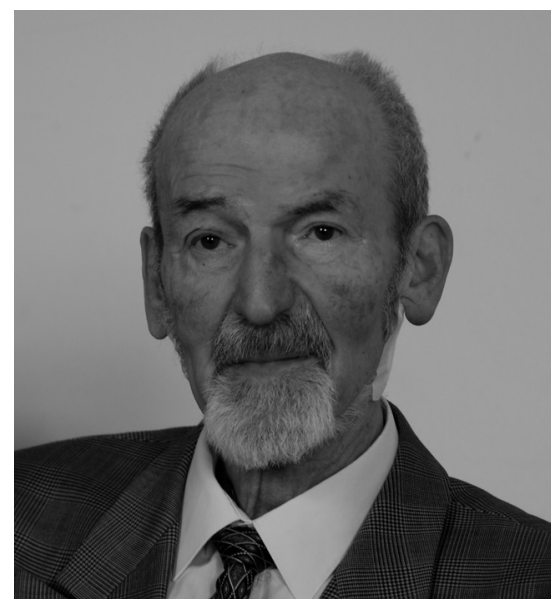
fundadas las cátedras de lengua española y literaturas española e hispanoamericana, también de lingüística española, sobre todo de su aspecto diacrónico.

En los años setenta del siglo pasado el profesor escribió uno de los primeros manuales de lengua española en Eslovenia, también es autor de importantes manuales de lingüística romance comparada y de numerosos artículos científicos y capítulos de monografías en Eslovenia y en el extranjero relativos a su campo de investigación que versa sobre cuatro temas principales. El primer tema ha sido la sintaxis del verbo italiano, sobre todo la esfera del pasado, su segundo campo de investigación científica se refiere a la dialectología de los dialectos vénetos en Istria y de los dialectos eslovenos occidentales. El tercer tema tiene que ver con la ya mencionada lingüística romance comparada y el cuarto es el estudio de la lengua española. Su gran amor fue la lengua de Cervantes, lo que atestiguan numerosos artículos publicados en Verba Hispanica, revista de la que fue cofundador $\mathrm{y}$, hasta su jubilación, director, siendo después miembro honorario.

Una de sus preocupaciones constantes fue la de mantener presentes en la Universidad de Ljubljana las demás lenguas romances. Así siguen funcionando exitosamente en nuestra facultad los lectorados de portugués y rumano, durante algunos años también funcionaron los de catalán, friulano y gallego.

El profesor Mitja Skubic fue director del Departamento de lenguas y literaturas romances, durante su docencia activa también director de la cátedra de 
lengua española. Sus estudiantes y colegas le recordamos como una persona comprometida con la filología y la enseñanza, una persona sincera y amable, un filólogo que, como un verdadero don Quijote, emprendía proyectos a primera vista irrealizables como han sido la fundación de los estudios hispánicos en Eslovenia y la revista científica Verba Hispanica que viene publicándose regularmente desde los inicios en los años noventa hasta hoy cuando se publica su número XXIII, dedicado a su memoria.

Branka Kalenić Ramšak Jasmina Markič 